Article

\title{
Tree Species and Their Space Requirements in Six Urban Environments Worldwide
}

\author{
Jens Dahlhausen *, Peter Biber, Thomas Rötzer, Enno Uhl and Hans Pretzsch \\ Chair for Forest Growth and Yield Science, Center of Life and Food Sciences Weihenstephan, \\ Technical University of Munich, Hans-Carl-von-Carlowitz-Platz 2, Freising 85354, Germany; \\ peter.biber@lrz.tum.de (P.B.); thomas.roetzer@lrz.tum.de (T.R.); enno.uhl@lrz.tum.de (E.U.); \\ hans.pretzsch@lrz.tum.de (H.P.) \\ * Correspondence: jens.dahlhausen@lrz.tum.de; Tel.: +49-8161-71-4713; Fax: +49-8161-71-4721
}

Academic Editors: Francisco Escobedo, Stephen John Livesley and Justin Morgenroth Received: 23 March 2016; Accepted: 19 May 2016; Published: 25 May 2016

\begin{abstract}
Urban trees have gained in importance during recent decades, but little is known about the temporal dynamic of tree growth in urban areas. The present study investigated the allometric relationships of stem diameter, tree height, and crown radius for six different tree species in six metropolises worldwide. Increment cores of the trees were used for identifying the relationship of basal area and basal area increment and for extrapolating the temporal dynamics for each species in relation to the allometric parameters and growth extensions. Space limitation and its direct influence on growth were quantified, as well as the aboveground woody biomass and the carbon storage capacity. The results show that, among the investigated species, Quercus nigra and Khaya senegalensis have the highest growth rates for stem diameter and crown radius, whereas Tilia cordata and Aesculus hippocastanum remain on a lower level. A significant reduction of tree growth due to restricted non-paved area was found for Aesculus hippocastanum and Khaya senegalensis. Estimations of aboveground biomass were highest for Quercus nigra and lowest for Tilia cordata. These results show the species-specific allometries of urban trees over a projected time period. Thus, the data set is highly relevant for planners and urban green managers.
\end{abstract}

Keywords: growing space requirements; metropolises; tree allometry; tree growth dynamics; urban trees; biomass

\section{Introduction}

Along with urban greening the interest in tree growth rapidly increased during recent decades. On the one hand, it can be explained by the fact that trees provide many ecosystem services and functions, like cooling the environment, filtering harmful particulate matter from the air, and having aesthetical and structural functions within build-up areas [1,2]. On the other hand, several disservices of urban trees exist, like litter fall, damage to foot paths, and fallen branches which cause additional costs $[1,3,4]$ and can endanger the public's safety.

Due to the benefits and disadvantages, the growth of urban trees and its space requirements are of high interest for urban planners and managers, as well as for arborculturists. First, it is important to know the future space requirements for the existing trees at a certain age. Second, for future planning the growing space requirements can be crucial for the choice of tree species before planting at a certain place [5]. Lastly, information on allometric relationships of urban trees is essential for the treatment measures of arborculturists for ensuring public safety. While there are several studies on forest trees, the space development of urban trees (solitary and open grown trees) is rarely known. Only a few studies [6,7] have investigated the differences in allometry and biomass between forest and urban trees. Our study aims at generating knowledge for urban trees by analyzing the space requirements, growth dynamics, and allometry of urban trees. 
Taking a deeper look at the benefits, one major benefit of urban trees is their carbon sequestration. The carbon storage capacity in turn is species-specific as Moser et al. [8], for example, showed for Robinia pseudoacacia and Tilia cordata in two German cities. They found a storage capacity of $461 \mathrm{~kg} \mathrm{C}$ per tree for Robinia pseudoacacia (mean age: 39 years) and with $196 \mathrm{~kg} \mathrm{C}$ a remarkable lower storage capacity for Tilia cordata (mean age: 41 years). Yoon et al. [9] estimated $24.9 \mathrm{t}$ of total average $\mathrm{C}$ storage for the tree species Acer buergerianum, Ginkgo biloba, Prunus yedoensis, and Zelkova serrata in Daegu, Korea, and $69.7 \mathrm{tC} \mathrm{ha}^{-1}$ for Platanus orientalis.

A key variable for space occupation is the crown size. Species-specific crown projection areas were found by Pretzsch et al. [10] while analyzing the growing space requirements of 22 tree species worldwide. They focused on crown size parameters and determined five different crown extension types. Large crown expansions, crown sizes, and tree heights result in higher service functions such as shading and filtering particulates. The dimensions of the crown are responsible for shading and cooling, two of the most important ecosystem services of trees in urban areas. They play an important role not only on a tree scale, cooling down the microclimate, but also on a street scale. This means that through shading, trees can increase human thermal comfort [11]. Further, on the city scale this service can reduce the urban heat island effect [4]. Additionally, the shading of street trees can reduce the maintenance costs for streets by protecting the asphalt from solar radiation. McPherson and Muchnick [3] report an extended lifetime of 10 to 25 years for road and pavement surfaces in California that are highly shaded in comparison to those that are not shaded.

A further benefit at all three aforementioned scales is the reduction of water runoff. Besides tree number, increasing tree and crown dimension also reduces water runoff due to higher evapotranspiration and interception rates. This reduction in the amount of runoff is species-specific $[4,12,13]$ and might also reduce stormwater runoff $[14,15]$.

While the studies mentioned above show that trees have many benefits, the related space requirements of urban trees are a potential conflict. On the one hand, space in urban areas is limited and therefore expensive. On the other hand, open space is essential for housing prices, especially close to the city center [16]. Thus, knowing the space requirements of certain tree species is of high interest for urban planning. As tree growth is species-specific, the growth rate and the spatial dimensions of different tree species in dependence on tree age could be essential information for urban planning. While the growth behavior (i.e., the crown radius, diameter at breast height or tree height) is well known for forest stands, little is known for solitary urban trees [17]. Studies have shown that information about growth dynamics of trees from forest stands cannot be directly transferred to urban trees [6]. This is due to the fact that in urban areas mainly mechanical stresses outweigh effects in forest stands, such as competition between trees or forest management measures [18].

The discussion about space requirements of trees in urban areas is not only relevant for the aboveground tree structure, but also for the rooting zone. The root growth is influenced by the available soil fraction, soil compaction, and the volume of root-penetrable soil [2]. Further, the effects of soil compaction, reduced soil volume, and paved surface are investigated in several studies $[18,19]$. If the soil volume is becoming too shallow, with time the roots start uplifting and cracking the pavement [20]. This in turn causes high costs for road or pavement maintenance, which is reported to be one of the first reasons for removing trees in urban areas [21].

In summary, while there are several studies dealing with space requirements of trees [10,22,23], the present study differs from the existing studies as it (1) is specific to urban trees; and (2) investigates the space requirements for six different tree species worldwide; and (3) provides a data set for each tree species representing the temporal dynamic of the tree structure. It is important to state that we do not see this study as a species comparison in the usual sense, which would not be possible with our data. Rather, we intend to compare different urban tree species, each under conditions where it can be considered to be typical and highly adapted. Based on the analyses, conclusions for space requirements of existing and planned tress, as well as conclusions on the potential benefits of urban trees, can be drawn. This leads to the following research questions: 
(1) Is there a relationship between space limitations of typical urban tree species (in the sense mentioned above) and allometric relationships?

(2) Does soil sealing limit the growth of urban trees?

(3) How do typical urban tree species (in the sense mentioned above) differ in terms of aboveground biomass and carbon storage?

\section{Materials and Methods}

\subsection{Data Acquisition}

For this study we used data from urban trees that were collected in six metropolises worldwide. The data are a subset from samples acquired in the overarching project Response of Urban Trees on Climate Change funded by the AUDI Environmental Foundation. The field campaigns took place between October 2010 and June 2014 in the cities of Berlin, Brisbane, Hanoi, Houston, Munich, and Paris. Altogether, our data comprise 1097 trees, with an average of 183 trees per city, with a minimum of 126 (Brisbane) and a maximum of 240 trees (Berlin). In each city the most common local urban tree species was chosen. While the overarching project included trees in the city centers, suburban zones, and in rural outskirts, only the former were selected for the study at hand.

Selecting criteria for sample trees were: (1) health; and (2) that the trees were not pruned. An overview of the selected cities and species is given in Table 1.

Table 1. Sample description of tree species, within the cities, geography (latitude, longitude), sampling size, and time. Only trees in an urban environment are considered.

\begin{tabular}{ccccccc}
\hline Species & Common Name & City & Country & Location & $\begin{array}{c}\text { Number } \\
\text { of Trees }\end{array}$ & Sampling Time \\
\hline $\begin{array}{c}\text { Aesculus } \\
\text { hippocastanum L. }\end{array}$ & Horse-chestnut & Munich & Germany & $\begin{array}{c}48^{\circ} 8^{\prime} \mathrm{N} \\
11^{\circ} 35^{\prime} \mathrm{E}\end{array}$ & 231 & 2013 \\
\hline $\begin{array}{c}\text { Araucaria } \\
\text { cunninghamii }\end{array}$ & Hoop pine & Brisbane & Australia & $\begin{array}{c}27^{\circ} 28^{\prime} \mathrm{S} \\
153^{\circ} 1^{\prime} \mathrm{E}\end{array}$ & 126 & 2013 \\
AITON ex. D.DON & African mahogany & Hanoi & Vietnam & $\begin{array}{c}21^{\circ} 2^{\prime} \mathrm{N} \\
105^{\circ} 51^{\prime} \mathrm{E}\end{array}$ & 163 & 2012 \\
\hline $\begin{array}{c}\text { Khaya senegalensis } \\
\text { (DESR.) A.JUSS. }\end{array}$ & London plane & Paris & France & $\begin{array}{c}48^{\circ} 51^{\prime} \mathrm{N} \\
2^{\circ} 21^{\prime} \mathrm{E}\end{array}$ & 171 & 2013 \\
\hline $\begin{array}{c}\text { Platanus } \text { hispanica } \\
\text { MÜNCHH. }\end{array}$ & Water oak & Houston & USA & $\begin{array}{c}29^{\circ} 45^{\prime} \mathrm{N} \\
95^{\circ} 23^{\prime} \mathrm{W}\end{array}$ & 166 & 2014 \\
\hline $\begin{array}{c}\text { Quercus nigra L. } \\
\text { Milia cordata MILL. }\end{array}$ & Small-leaved lime & Berlin & Germany & $\begin{array}{r}52^{\circ} 31^{\prime} \mathrm{N} \\
13^{\circ} 24^{\prime} \mathrm{E}\end{array}$ & 240 & $2010,2012,2013$ \\
\hline
\end{tabular}

For each tree, diameter increment time series are available from two increment cores taken from orthogonal directions at breast height. As the tree diameter $d$ was measured, the diameter time series could be reconstructed backwards. Additional information about the sampling is described in Pretzsch et al. [10]. In the study at hand we transformed the diameter time series into basal area $(b a)$ and basal area increment (iba) time series, because in contrast to diameter increment, basal area increment is directly related to a tree's biological production [24] and thus more appropriate for the allometric analyses shown below. Total tree height $(h)$ and height to crown base $(h c b)$ are also available, together with crown radii $(r)$ measured in the eight cardinal and sub-cardinal directions, as suggested by Preuhsler [25]. The mean crown radius ( $c r$ ) was calculated as the quadratic mean of these eight crown radii in Equation (1).

$$
c r=\sqrt{\left(r_{N}^{2}+r_{N W}^{2}+\ldots+r_{N E}^{2}\right) / 8}
$$


Based on the mean crown radius, the crown projection area is then given by the following Equation (2), ensuring a bias-free transition between crown radius to crown projection area.

$$
c p a=c r^{2} \times \pi
$$

Moreover, tree height and height to crown base $(c b)$ were recorded by using a Vertex IV ultrasonic hypsometer.

In order to quantify a tree's spatial confinement by soil sealing like asphalted pavement or concrete surfaces, the unsealed area around the stem base was measured for each tree in four cardinal directions with a measuring tape. We used this information for calculating the variable $S C O N$, which expresses the degree of confinement due to soil sealing. It is calculated as follows in Equation (3):

$$
S C O N=1-\frac{n p a}{c p a}
$$

where cpa is the crown projection area $\left(\mathrm{m}^{2}\right)$ and $n p a$ is the measured non-paved area $\left(\mathrm{m}^{2}\right)$. Table 2 gives an overview of the tree characteristics covered by our data. A. cunninghamii covers the broadest diameter range $(15.7-129.5 \mathrm{~cm})$ and the largest diameter was measured for $P$. $x$ hispanica with $144 \mathrm{~cm}$. The largest maximum $c r$ with $14.8 \mathrm{~m}$ was also measured for $P$. $x$ hispanica. The tallest tree was of the species $K$. senegalensis with $36 \mathrm{~m}$, and this species also showed the highest range for ring widths. $A$. hippocastanum (232 years) and P. $x$ hispanica (234 years) covered the largest age range within our sampled trees. Npa was largest for A. cunninghamii with $410 \mathrm{~m}^{2}$, and smallest for T. cordata, A. hippocastanum, and K. senegalensis with 0.5 to $100 \mathrm{~m}^{2}$.

\subsection{Allometric Analyses}

Plant allometry is a concept that is used in this study to relate tree dimensions to each other as well as to relate plant size and increment. It has a strong theoretical foundation [26-28] which, together with its mathematical compactness, makes it a powerful tool for applications in science and practice [22]. It is very common to use the double-logarithmic form of the allometric equation, especially in empirical study, because it makes the relation between two plant variables $x$ and $y$, say $x=$ stem diameter, $y=$ height, accessible to linear regression models (Equation (4)):

$$
\ln y=k+c \cdot \ln x
$$

Here, the constants $\mathrm{c}$ and $e^{k}$ are the allometric scaling coefficient and the allometric factor, respectively. Embedded in this context, the backbone of our analyses is a linear mixed effects model (Equation (5)), which describes the allometric relationship between the annual basal area increment $i b a\left(\mathrm{~cm}^{2} / \mathrm{y}\right)$ and the corresponding basal area $b a\left(\mathrm{~cm}^{2}\right)$ at the beginning of the corresponding year.

$$
\ln i b a_{i j}=\beta_{0}+\beta_{1} \cdot \ln b a_{i j}+b_{i}+\varepsilon_{i j}
$$

This model was fitted to the retrospective tree growth data of each city separately. The indexes $i$ and $j$ represent the $j^{\text {th }}$ observation of the $\mathrm{i}^{\text {th }}$ tree, $\beta_{0}$ and $\beta_{1}$ are fixed effect parameters, $b_{i}$ is a random effect on tree level with $b_{i} \sim N\left(0, \tau^{2}\right)$, and $\varepsilon_{i j}$ are i.i.d. errors.

In order to estimate the influence of spatial restriction on basal area increment we extended this model to Equation (6) by including the variable SCON which describes the confinement of a tree's growing area by soil sealing as defined in Equation (3) above.

$$
\ln i b a_{i j}=\beta_{0}+\beta_{1} \cdot \ln b a_{i j}+\beta_{2} \cdot S C O N_{i}+b_{i}+\varepsilon_{i j}
$$


Table 2. Tree characteristics for each species.

\begin{tabular}{|c|c|c|c|c|c|c|c|c|c|c|c|c|c|c|c|c|c|c|c|c|c|}
\hline \multirow{2}{*}{ Species } & \multicolumn{3}{|c|}{$d(\mathrm{~cm})$} & \multicolumn{3}{|c|}{$c r(\mathrm{~m})$} & \multicolumn{3}{|c|}{$h(\mathrm{~m})$} & \multicolumn{3}{|c|}{$r w(\mathrm{~mm})^{1}$} & \multicolumn{3}{|c|}{ age (year) } & \multicolumn{3}{|c|}{$n p a\left(\mathrm{~m}^{2}\right)^{2}$} & \multicolumn{3}{|c|}{ SCON } \\
\hline & Min & Mean & Max & Min & Mean & Max & Min & Mean & $\operatorname{Max}$ & Min & Mean & $\operatorname{Max}$ & Min & Mean & $\overline{\operatorname{Max}}$ & Min & Mean & $\operatorname{Max}$ & Min & Mean & $\operatorname{Max}$ \\
\hline $\begin{array}{l}\text { Aesculus } \\
\text { hippocastanum }\end{array}$ & 27.2 & 63.6 & 116.9 & 2.9 & 5.5 & 9.0 & 7.4 & 16.1 & 27.2 & 0.32 & 1.61 & 7.91 & 17 & 118 & 249 & 1.00 & 15.08 & 100.00 & 0.00 & 0.83 & 0.99 \\
\hline $\begin{array}{l}\text { Araucaria } \\
\text { cunninghamii }\end{array}$ & 15.7 & 40.7 & 129.5 & 1.6 & 3.5 & 11.6 & 6.1 & 17.3 & 33.5 & 0.75 & 3.63 & 6.50 & 19 & 52 & 182 & 3.90 & 79.85 & 410.00 & 0.00 & 0.36 & 0.96 \\
\hline $\begin{array}{l}\text { Khaya } \\
\text { senegalensis }\end{array}$ & 44.1 & 73.4 & 123.1 & 3.1 & 6.5 & 11.7 & 14.1 & 22.6 & 36 & 0.63 & 5.30 & 18.55 & 13 & 53 & 142 & 1.00 & 11.18 & 100.00 & 0.07 & 0.91 & 1.00 \\
\hline $\begin{array}{l}\text { Platanus } x \\
\text { hispanica }\end{array}$ & 40.3 & 64.8 & 144.0 & 2.7 & 6.6 & 14.8 & 6.84 & 18.8 & 34.5 & 0.41 & 2.54 & 10.93 & 20 & 104 & 254 & 2.00 & 33.59 & 140.00 & 0.20 & 0.78 & 0.99 \\
\hline Quercus nigra & 34.2 & 61.5 & 98.0 & 3.4 & 7.1 & 11.9 & 10 & 15.9 & 22.8 & 0.82 & 3.96 & 12.55 & 16 & 52 & 101 & 1.50 & 33.82 & 150.00 & 0.00 & 0.66 & 0.98 \\
\hline Tilia cordata & 25.2 & 45.5 & 81.1 & 2.5 & 5.1 & 9.5 & 8.1 & 16.3 & 29.1 & 0.22 & 1.63 & 5.38 & 34 & 85 & 194 & 0.50 & 25.31 & 100.00 & 0.00 & 0.81 & 1.00 \\
\hline
\end{tabular}

${ }^{1} \mathrm{n}$ rw A. hippocastanum $=193$, A. cunninghamii $=62$, K. senegalensis $=144$, P. $x$ hispanica $=133$, Q. nigra $=183$, T. cordata $=227 ;{ }^{2} \mathrm{n}$ npa A. hippocastanum $=231$, A. cunninghamii $=126$, K. senegalensis $=163, P . x$ hispanica $=171, Q$. nigra $=166, T$. cordata $=144 . d$ : diameter at breast height $(1.3 \mathrm{~m}), c r$ : crown radius, $h$ : tree height, rw: ring width, tree age, $n p a$ : non-paved area, and SCON: degree of a trees spatial confinement.2.2. Allometric Analyses 
When fitting this model, we restricted the tree growth data to the years after 1980, because npa was only measured once at survey time, and we refrained from assuming it was in effect for four decades or more. With preliminary versions of Equation (6) we also tested for the presence of interactions between SCON and $b a$, which, however, were not significant. Due to the comparably short time series from the restricted data set, we did not obtain plausible estimates for the allometric slope $\beta_{1}$ when fitting Equation (6). We therefore decided to keep the allometric slopes $\beta_{1}$ from the fitted Equation (6), and to use the following model (Equation (7)) for assessing the influence of SCON:

$$
\ln i b a_{i j}-\beta_{1} \cdot \ln b a_{i j}=\alpha_{0}+\alpha_{1} \cdot S C O N_{i}+b_{i}+\varepsilon_{i j}
$$

Here, $\alpha_{0}$ and $\alpha_{1}$ are the fixed effects parameters to be estimated with the model. Thus, for estimating a tree's basal area increment $i b a$ from its basal area $b a$ and a given spatial confinement $S C O N$, without considering tree-specific random effects, the Equation (8) can be used:

$$
\widehat{\ln i b a}=\alpha_{0}+\beta_{1} \cdot \ln b a+\alpha_{1} \cdot \operatorname{SCON}
$$

Analogously, if the spatial confinement effect shall not be considered explicitly in the estimation of basal area increment, the fit results of Equation (6) can be applied with Equation (9):

$$
\widehat{\ln i b a}=\beta_{0}+\beta_{1} \cdot \ln b a
$$

Both equations allow for estimating a tree's temporal basal area development by using them in the following alternative serial calculations (Equations (10) and (11)):

$$
\begin{gathered}
b a_{t+1}=b a_{t}+e^{\alpha_{0}+\beta_{1} \cdot \ln b a_{t}+\alpha_{1} \cdot S C O N} \\
b a_{t+1}=b a_{t}+e^{\beta_{0}+\beta_{1} \cdot \ln b a_{t}}
\end{gathered}
$$

The index $t$ represents one point of time, $t+1$ is the point of time one year later. Starting with a given initial value for basal area $b a_{t_{0}}$, basal area development for any reasonable time span can be projected. As a common initial value we chose $b a_{t_{0}}=78.54 \mathrm{~cm}^{2}$, which corresponds to a diameter at breast height of $10 \mathrm{~cm}$, a size at which urban trees are often planted. We projected basal area development for 200 years, in case of Equation (10) with three different values for SCON, representing total absence of non-paved area limitation, medium, and maximum limitation as found in the data for each tree species.

In order to link basal area with vertical and horizontal space requirements, we fitted two additional allometric models (Equations (12) and (13)):

$$
\begin{aligned}
& \ln h_{i}=\beta_{0}+\beta_{1} \cdot \ln d_{i}+\varepsilon_{i} \\
& \ln c r_{i}=\beta_{0}+\beta_{1} \cdot \ln d_{i}+\varepsilon_{i}
\end{aligned}
$$

where $h$ is tree height, $\mathrm{cr}$ crown radius, and d is a tree's diameter at breast height. The latter can be easily obtained if basal area is known by $d=\sqrt{b a \cdot 4 / \pi}$. Both models were fitted city-wise by ordinary least squares (OLS) regression. As only one height and crown radius per tree were available from the field survey, including tree-level random effects was not necessary.

\subsection{Tree Biomass Estimates}

Based on the statistical models shown above, temporal tree development in terms of basal area (diameter), height, and crown radius can be estimated. In order to link those projected tree dynamics to biomass and carbon storage, the tree biomass has to be estimated. We focus on total aboveground woody biomass $(w)$, which can usually be estimated as a function of stem diameter at breast height $(d)$ and tree height $(h)$. 
For all species covered by this study, such equations for estimating $w$ were available as by Jenkins et al. [29] for A. hippocastanum, Eamus et al. [30] for A. cunninghamii, Clément [31] for K. senegalensis, Yoon et al. [9] for P. x hispanica, Clark et al. [32] for Q. nigra, and Čihák et al. [33] for T. cordata.

The biomass equations are based on forest tree data, and thus on trees under competition by other trees, excepting the equation for P. $x$ hispanica, which is based on urban tree data. Trees in urban areas are mostly open-grown without competing trees, which calls the applicability of the above-mentioned equations into question. To account for this we apply a factor of 0.8 to the traditional biomass equations.

Based on the aboveground biomass we determine the related carbon storage by multiplying the biomass with 0.5 [34].

\section{Results}

\subsection{Growth and Space Requirements of Urban Trees Based on Allometric Relationships}

In Table 3 the results of the linear regression models, one per species, for the 'basal area-basal area increment' allometric relationship Equation (5) are shown for all tree species. The allometric exponent $\beta_{1}$ was in all cases different from zero on a significance level $p<0.0001$ and varied from $\beta_{1}=0.4747$ for A. cunninghamii in Brisbane to $\beta_{1}=-0.0057$ for $A$. hippocastanum in Munich. The scaling parameter $\beta_{0}$ was in a range between $\beta_{0}=-4.5288$ for $A$. cunninghamii and $\beta_{0}=-5.8743$ for $T$. cordata. $\tau^{2}$ describes the variance of the random effects on tree level.

Table 3. Linear regression models for the basal area to basal area increment allometry (Equation (5)) for all six species (ordered according to latitude).

\begin{tabular}{cccccccc}
\hline Species & $\boldsymbol{\beta}_{\mathbf{0}}$ & $\mathrm{SE}\left(\boldsymbol{\beta}_{\mathbf{0}}\right)$ & $\boldsymbol{p}\left(\boldsymbol{\beta}_{\mathbf{0}}\right)$ & $\boldsymbol{\beta}_{\mathbf{1}}$ & $\mathrm{SE}\left(\boldsymbol{\beta}_{\mathbf{1}}\right)$ & $\boldsymbol{p}\left(\boldsymbol{\beta}_{\mathbf{1}}\right)$ & $\boldsymbol{\tau}^{\mathbf{2}}$ \\
\hline Araucaria cunninghamii & -4.5288 & 0.0533 & $<0.0001$ & 0.4747 & 0.0127 & $<0.0001$ & 0.0637 \\
Khaya senegalensis & -4.9173 & 0.0523 & $<0.0001$ & 0.0028 & 0.0260 & 0.9145 & 0.1711 \\
Quercus nigra & -4.8455 & 0.0416 & $<0.0001$ & 0.1077 & 0.0097 & $<0.0001$ & 0.2201 \\
Platanus x hispanica & -5.5322 & 0.0570 & $<0.0001$ & 0.0325 & 0.0138 & 0.0185 & 0.3447 \\
Aesculus hippocastanum & -5.8001 & 0.0322 & $<0.0001$ & -0.0057 & 0.0084 & 0.4924 & 0.1535 \\
Tilia cordata & -5.8743 & 0.0302 & $<0.0001$ & 0.1425 & 0.0061 & $<0.0001$ & 0.1453 \\
\hline
\end{tabular}

Parameter estimates $\left(\beta_{0}, \beta_{1}\right)$ with standard errors $(\mathrm{SE})$, significances $(p)$, and the variance of the random effect $\left(\tau^{2}\right)$.

Further model results of the allometric relationships between "tree height-stem diameter" and "crown radius-stem diameter" are shown in Tables 4 and 5.

Table 4. Linear regression models for stem diameter $(d)$ to tree height $(h)$ Equation (12) for all six species (ordered according to latitude).

\begin{tabular}{ccccccccc}
\hline Species & $\boldsymbol{\beta}_{\mathbf{0}}$ & SE & $\boldsymbol{\beta}_{\mathbf{1}}$ & SE & $\boldsymbol{r}^{\mathbf{2}}$ & $\mathbf{R S E}$ & $\boldsymbol{F}$ & $\boldsymbol{p}$ \\
\hline Araucaria cunninghamii & 0.6599 & 0.1417 & 0.5945 & 0.0391 & 0.6510 & 0.1955 & 231.72 & $<0.0001$ \\
Khaya senegalensis & -0.1319 & 0.2416 & 0.7560 & 0.0566 & 0.5550 & 0.1510 & 178.51 & $<0.0001$ \\
Quercus nigra & 1.8093 & 0.2149 & 0.2312 & 0.0524 & 0.1060 & 0.1521 & 19.47 & $<0.0001$ \\
Platanus x hispanica & 0.9630 & 0.2343 & 0.4708 & 0.0566 & 0.2900 & 0.2135 & 69.07 & $<0.0001$ \\
Aesculus hippocastanum & 0.1092 & 0.1986 & 0.6410 & 0.0480 & 0.4370 & 0.1651 & 178.03 & $<0.0001$ \\
Tilia cordata & 1.6825 & 0.2246 & 0.2868 & 0.0591 & 0.0900 & 0.1976 & 23.56 & $<0.0001$
\end{tabular}

Parameter estimates $\left(\beta_{0}, \beta_{1}\right)$ with standard errors (SE), coefficients of determination $\left(r^{2}\right)$, residual standard errors (RSE), $F$-values, and significances $(p)$. 
Table 5. Linear regression models for stem diameter (d) to crown radius (cr) Equation (13) for all six species (ordered according to latitude).

\begin{tabular}{ccccccccc}
\hline Species & $\boldsymbol{\beta}_{\mathbf{0}}$ & SE & $\boldsymbol{\beta}_{\mathbf{1}}$ & SE & $\boldsymbol{r}^{\mathbf{2}}$ & RSE & $\boldsymbol{F}$ & $\boldsymbol{p}$ \\
\hline Araucaria cunninghamii & -1.3881 & 0.1209 & 0.7147 & 0.0333 & 0.7880 & 0.1668 & 460.15 & $<0.0001$ \\
Khaya senegalensis & -0.7786 & 0.3394 & 0.6134 & 0.0793 & 0.2710 & 0.2157 & 59.79 & $<0.0001$ \\
Quercus nigra & -0.7962 & 0.2130 & 0.6691 & 0.0519 & 0.5030 & 0.1508 & 165.96 & $<0.0001$ \\
Platanus x hispanica & -0.5391 & 0.2298 & 0.5775 & 0.0556 & 0.3900 & 0.2094 & 108.06 & $<0.0001$ \\
Aesculus hippocastanum & -0.9663 & 0.1695 & 0.6431 & 0.0410 & 0.5180 & 0.1409 & 245.77 & $<0.0001$ \\
Tilia cordata & -0.0336 & 0.1929 & 0.4342 & 0.0507 & 0.2360 & 0.1675 & 73.27 & $<0.0001$ \\
\hline
\end{tabular}

Parameter estimates $\left(\beta_{0}, \beta_{1}\right)$ with standard errors (SE), coefficients of determination $\left(r^{2}\right)$, residual standard errors (RSE), $F$-values, and significances $(p)$.

The relationship of stem diameter to tree height shows the highest scaling parameter for K. senegalensis $\left(\beta_{1}=0.76\right)$ in Hanoi and lowest for $Q$. nigra $\left(\beta_{1}=0.23\right)$ in Houston. For $\beta_{0}$ only K. senegalensis $\left(\beta_{0}=-0.13\right)$ shows a negative value, all other species have positive values with the highest for $Q$. nigra $\left(\beta_{0}=1.81\right)$. In comparison to this, allometric exponents for the relationship of stem diameter to crown radius are in a smaller range. The scaling factors are positive for all species and in a very narrow range ( $\beta_{1}=0.43$ for $T$. cordata, $\beta_{0}=0.71$ for $A$. cunninghamii). The lowest allometric exponent is $\beta_{0}=-1.39$ for $A$. cunninghamii and the highest is for T. cordata with $\beta_{0}=-0.03$.

Based on the allometric relationship of 'basal area-basal area increment' and the estimated coefficients (Table 3) the diameter growth of a distinct tree species at a specific age can be projected. It has to be mentioned that the term age concisely means the age at breast height of the tree. Further, by taking the results of the other allometric relationships 'tree height-stem diameter' and 'crown radius-stem diameter' (Tables 4 and 5) into account this kind of time-specific extrapolation can be extended to the tree height and the crown diameter growth.

A time-series for 200 years was calculated on the base of a stem diameter of $10 \mathrm{~cm}$ starting in year 0 . The results for the three estimated parameters $d, c r, h$, and for all six tree species are shown in Figure 1. For all three allometric relationships a visualization of the standard errors of $\beta_{1}$ is added in the appendix (Figure A1).

For the stem diameter growth (Figure 1a) K. senegalensis in Hanoi shows the highest growth over time, while the lowest was calculated for T. cordata in Munich. At an age of 100 years, for example, T. cordata has a diameter at breast height of $42 \mathrm{~cm}$, whereas $K$. senegalensis is about $92 \mathrm{~cm}$. Similar findings can be seen for the temporal dynamics of the tree height-diameter relationship (Figure 1b). $K$. senegalensis marks the upper level, in contrast the lowest level, which is obvious for A. hippocastanum until an age of 130 years. Between this range the species $Q$. nigra, T. cordata, and P. $x$ hispanica remain at the lower border, unlike A. cunninghamii, which is close to the level of $K$. senegalensis. A different temporal distribution was found for the crown radius (Figure 1c). The upper limit is represented by Q. nigra in Houston, having a $c r$ of about $9 \mathrm{~m}$ at an age of 100 years. In contrast, at the same time the species A. cunninghamii in Brisbane, T. cordata in Berlin, and A. hippocastanum in Munich have crown radii of about $5 \mathrm{~m}$. The study is a comparison of well-adapted trees for specific regions, but not a mere species comparison. 


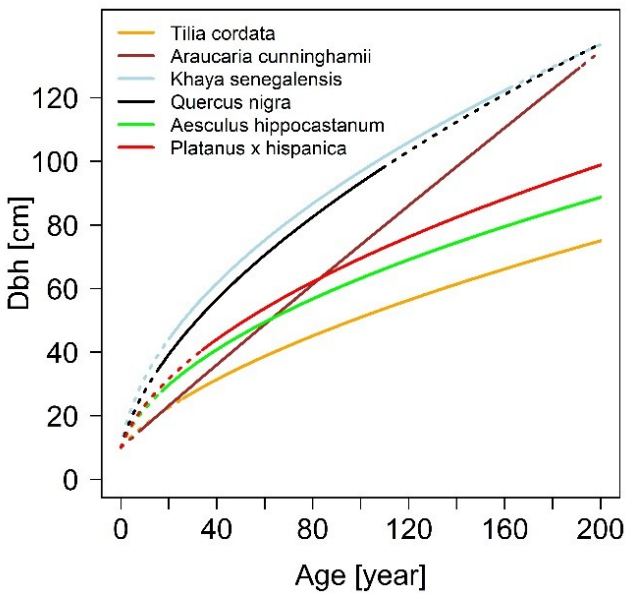

(a)

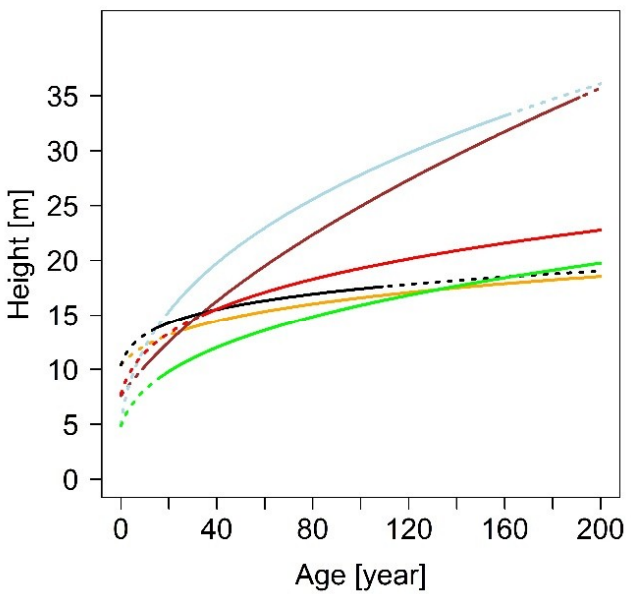

(b)

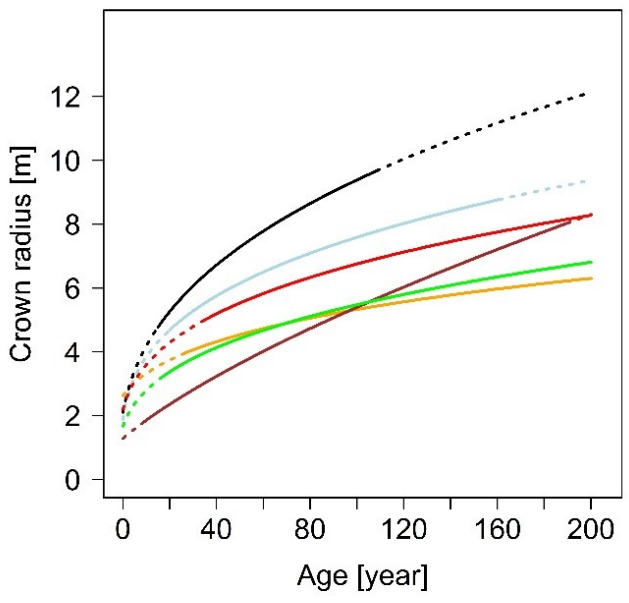

(c)

Figure 1. Allometric relationships for (a) diameter at breast height; (b) tree height; and (c) crown radius based on allometric model parametrizations for all six tree species (based on values of Tables 3-5). Dotted lines show projections which are not covered by measured data. 


\subsection{Impact of Paved Surface Area on Urban Tree Growth}

As mentioned above, urban trees are often limited by non-paved area, especially in city centers. During our measurements the "non-paved surface area" (npa) was also recorded for tree species, if possible. This parameter, in the form of SCON Equation (3), is included in linear mixed effect models, one per species, for the ba-iba allometry Equation (7). The output of the models can be seen in Table 6, and the significances of $\alpha_{1}$ indicate that the additional factor SCON is only significant for two species, K. senegalensis and A. hippocastanum. Q. nigra was also significant, but the results are not further shown, due to a not-plausible positive coefficient $\alpha_{1}$, which can be explained by a very narrow range of the recorded values for $n p a$.

Table 6. Linear regression results for the basal area-basal area increment allometry and the influence of SCON Equation (7) for all six species (ordered according to latitude).

\begin{tabular}{cccccccc}
\hline Species & $\alpha_{\mathbf{0}}$ & SE $\left(\boldsymbol{\alpha}_{\mathbf{0}}\right)$ & $\boldsymbol{p}\left(\boldsymbol{\alpha}_{\mathbf{0}}\right)$ & $\boldsymbol{\alpha}_{\mathbf{1}}$ & $\mathrm{SE}\left(\boldsymbol{\alpha}_{\mathbf{1}}\right)$ & $\boldsymbol{p}\left(\boldsymbol{\alpha}_{\mathbf{1}}\right)$ & $\tau^{\mathbf{2}}$ \\
\hline A. cunninghamii & -4.6109 & 0.0769 & 0.0000 & -0.0005 & 0.1116 & 0.9964 & 0.0765 \\
K. senegalensis & -3.4053 & 0.3660 & 0.0000 & -1.4998 & 0.3928 & 0.0002 & 0.2249 \\
Q. nigra & -5.5567 & 0.1794 & 0.0000 & 0.7648 & 0.2221 & 0.0007 & 0.2222 \\
P. x hispanica & -4.9857 & 0.2699 & 0.0000 & -0.5632 & 0.3251 & 0.0856 & 0.3752 \\
A. hippocastanum & -5.3079 & 0.0997 & 0.0000 & -0.4056 & 0.1306 & 0.0022 & 0.2028 \\
T. cordata & -5.7364 & 0.1721 & 0.0000 & -0.1285 & 0.1954 & 0.5119 & 0.1868
\end{tabular}

Parameter estimates $\left(\alpha_{0}, \alpha_{1}\right)$ with standard errors (SE), significances $(p)$, and the variance of the random effect $\left(\tau^{2}\right)$.

The effect of the degree of spatial confinement by soil sealing on the parameters diameter, height, and crown radius for the species K. senegalensis in Hanoi and A. hippocastanum in Munich is depicted in Figure 2. Thereby three classes of the variable $S C O N$ : no limitation $(S C O N=0), 50 \%$ limitation $(S C O N=0.5)$, and high limitation $(S C O N=0.9)$ were considered.

For A. hippocastanum only a slight influence of the limitation factor can be seen. Still, the trees with the lowest degree of limitation show the highest growth levels. In contrast, for K. senegalensis a strong relationship between the non-paved area and the tree growth can be found. Thereby, all K. senegalensis trees were mid- to high-restricted. Due to this, only these two classes could be shown in Figure 2. To give an example of the influence of the restricted non-paved area, the tree height of a 100 year old high-limited tree is $60 \%$ of the tree height of a similar-aged medium-limited tree. For the stem diameter growth a value of $50 \%$ can be accounted. With increasing age, the growth of the trees is increasingly inhibited. These findings show that restricted npa influences tree growth, but that the effect is species-specific and can be weak, as in the case of A. hippocastanum in Munich, or strong, as in the case of K. senegalensis in Hanoi. These findings can be reported for five of the six investigated species (Table 6).

\subsection{Biomass and Carbon Storage Estimation for Urban Trees}

Finally, the aboveground woody biomass of the species was estimated by species-specific equations from literature. The amounts of produced above ground biomass clearly vary from species to species (Figure 3). A 100 year old T. cordata tree in Berlin has a biomass of $0.7 \mathrm{t}$ compared to a similar-aged Q. nigra tree in Houston with $3.3 \mathrm{t}$. The differences in the total aboveground biomass of the tree species increase with the age of the trees. Lowest biomass productivity by the age of 160 years is shown by T. cordata in Berlin and P. $x$ hispanica in Paris with $1.3 \mathrm{t}$ and $2.5 \mathrm{t}$ per tree, respectively. For the same age, A. hippocastanum and K. senegalensis have a biomass of 3.5 and $4.2 \mathrm{t}$, respectively. With values of 5.2 and $5.9 \mathrm{t}$ per tree the highest biomass values are achieved by A. cunninghamii and Q. nigra. 


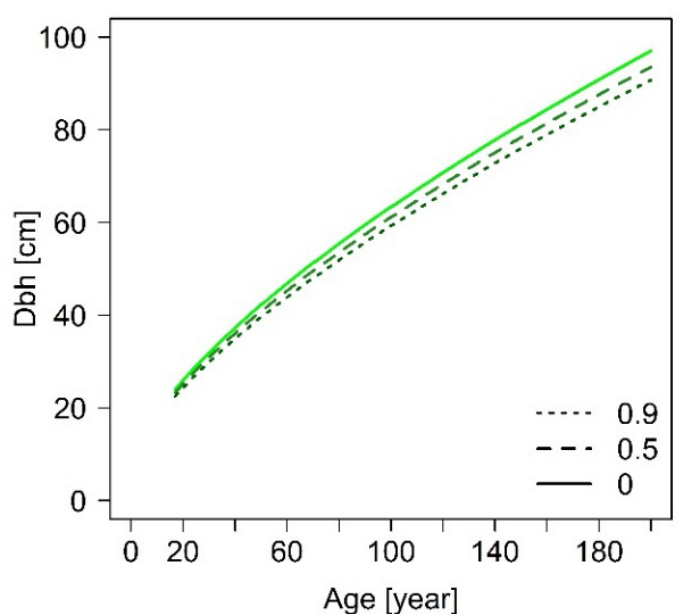

(a)

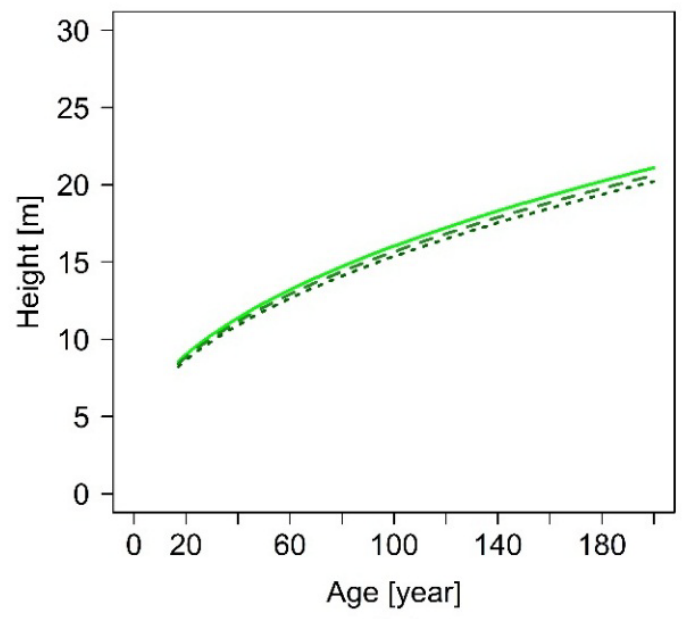

(b)

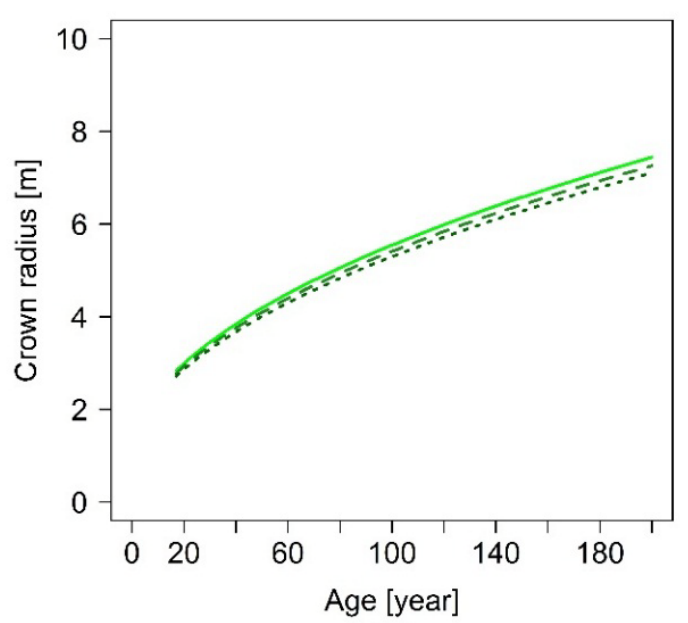

(c)

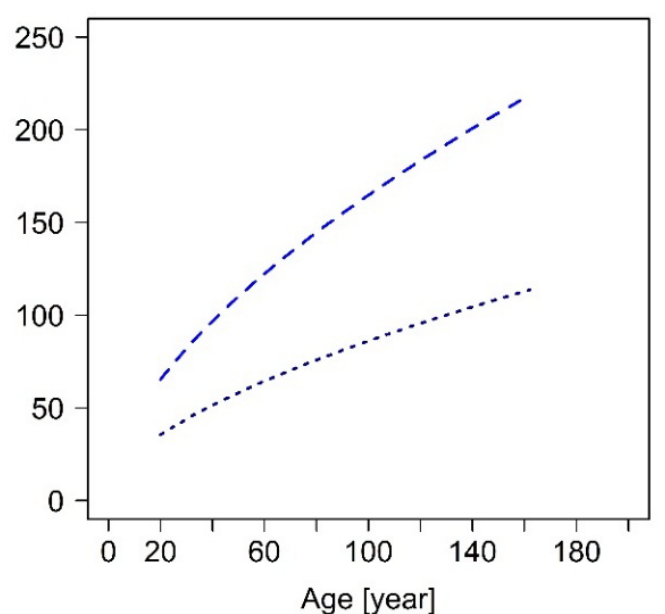

(d)

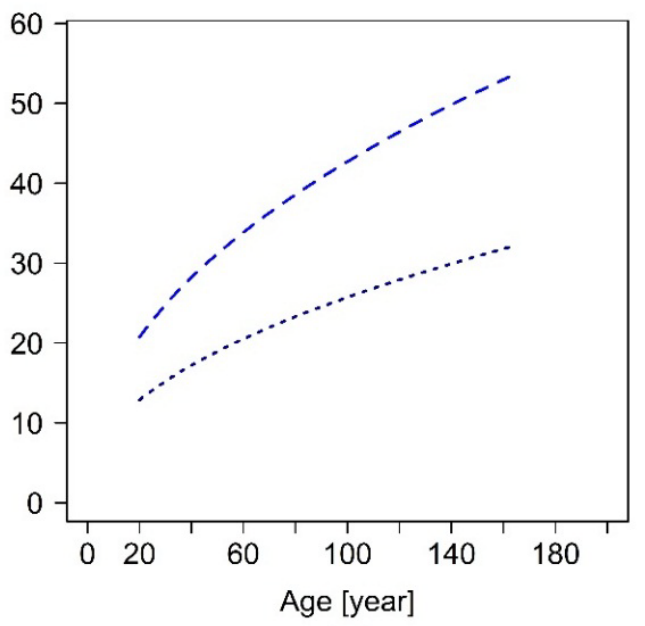

(e)

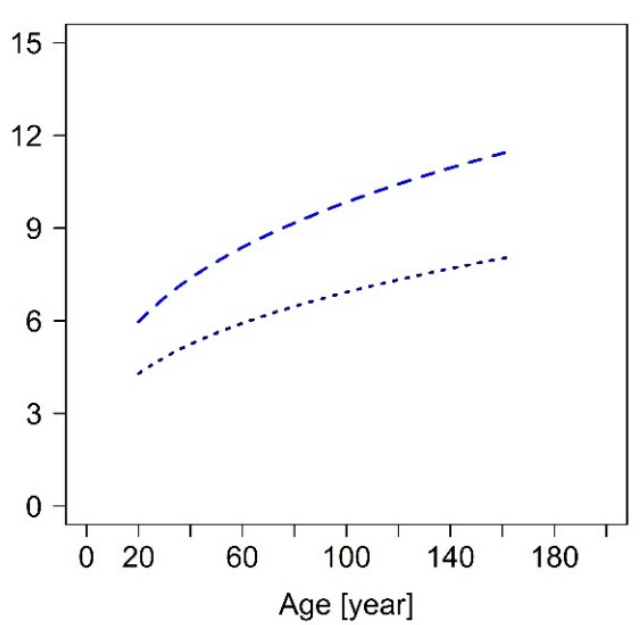

(f)

Figure 2. Effect of SCON on allometric growth relationships for diameter at breast height, tree height, and crown radius depending on age for the species Aesculus hippocastanum (panels a-c) and for Khaya senegalensis (panels d-f); solid line: no limitation, dashed line: 50\% limited, and dotted line: highly limited (90\%). 


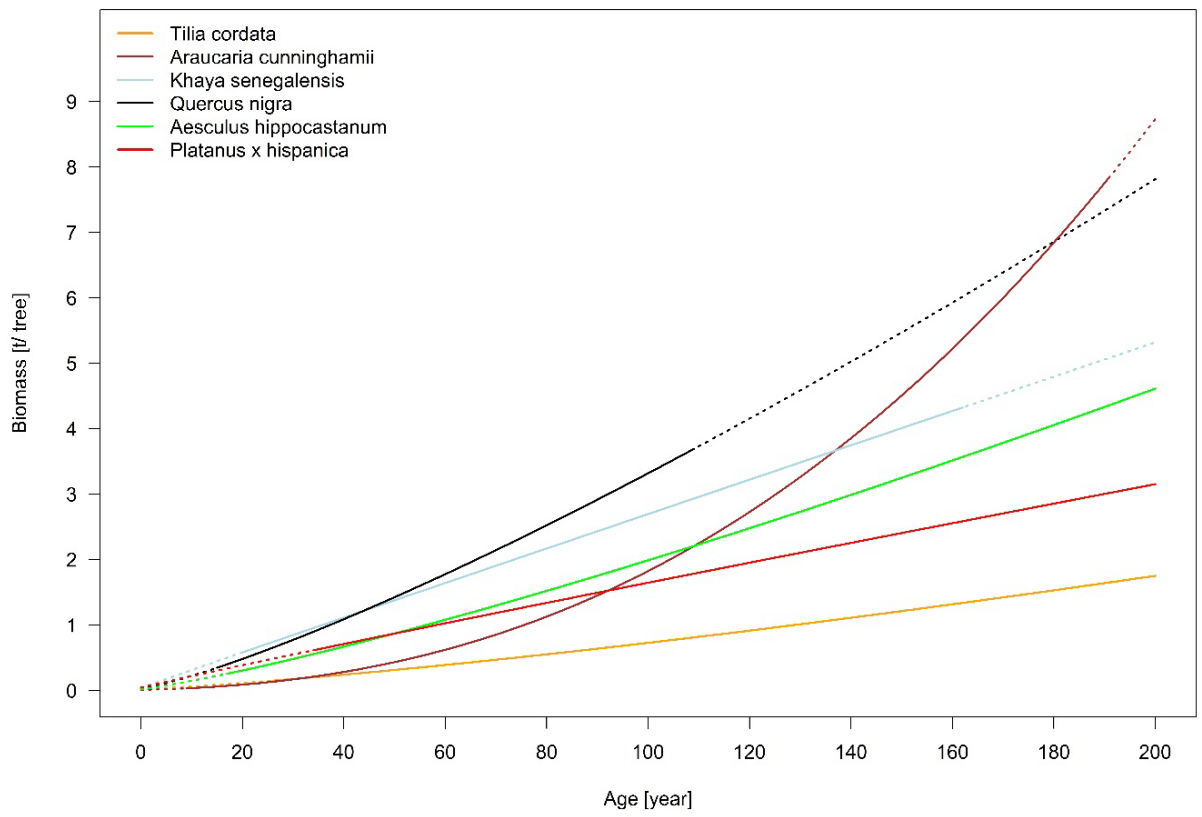

Figure 3. Estimated aboveground woody biomass for six tree species in urban environments, based on allometric equations. The data include the correction factor of 0.8 for transferring a stand biomass equation to urban trees. Dotted lines show projections which are not covered by measured data.

A comparison of the calculated carbon storage based on the measured tree parameters are shown in Figure 4, taking all available trees and the resulting average age into account (Tables 1 and 2). A. hippocastanum has the highest range from 122 to $4575 \mathrm{~kg}$ per tree and on average has $1106 \mathrm{~kg}$ per tree stored carbon; trees with lesser capacity include P. $x$ hispanica (188-3038 kg per tree), Q. nigra (133-2145 kg per tree), and K. senegalensis (290-2161 kg per tree), the lowest values, as well as the smallest range, are attributed to T. cordata (71-1087 kg per tree) and A. cunninghamii (12-3531 kg per tree). The difference between the carbon storage (Figure 4) and the estimated biomass (Figure 3) is due to a variation in diameter at breast height $(d b h)$-range between the species, which can be seen in Table 2.

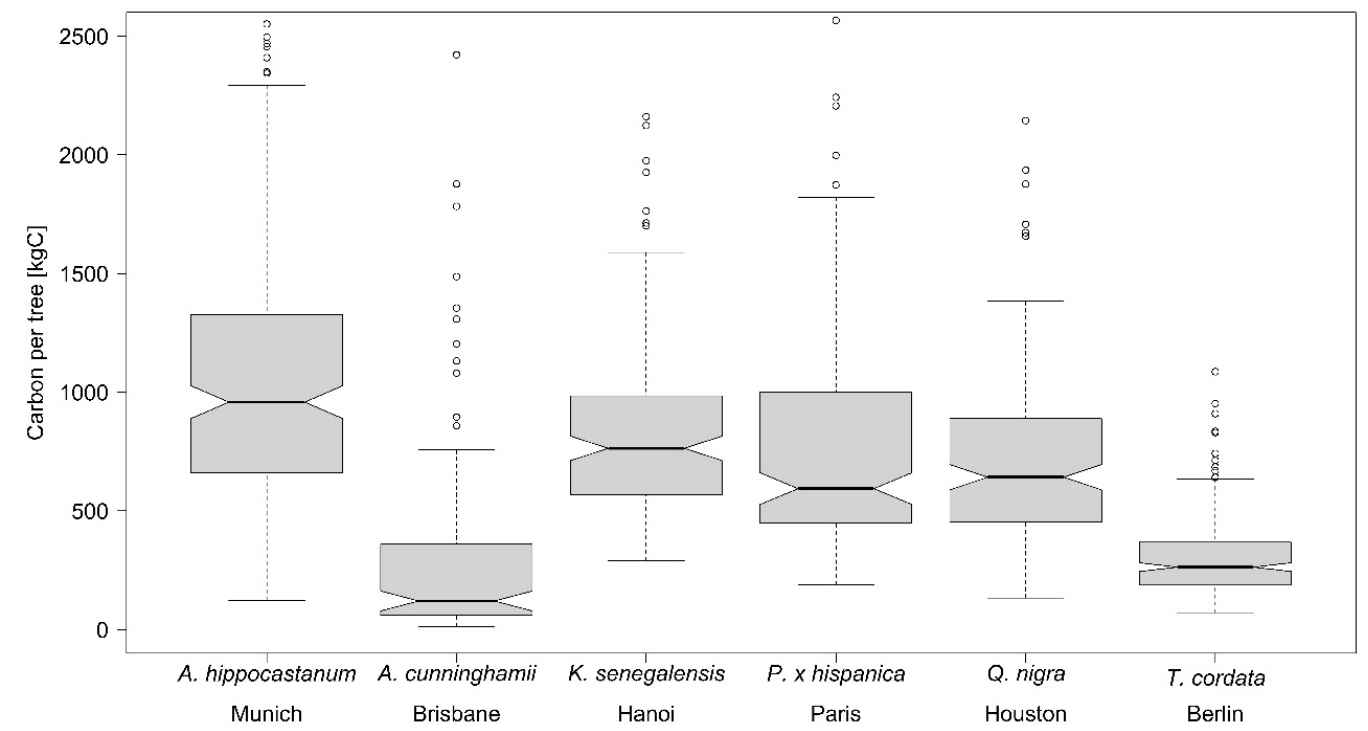

Figure 4. Carbon storage capacity of the investigated tree species in urban areas (cities), based on the measured data for diameter and tree height. 


\section{Discussion}

\subsection{Generalizabilty of the Identified Relationships}

As mentioned in the introduction, this study cannot be interpreted as a usual species comparison, which would require a research design where the same set of species is observed under the same range of conditions. Our point is to compare urban tree growth and space requirements across a broad geographic climatic gradient based on a set of species that can be considered to be typical and highly adapted to the respective conditions. Some of the data we use are a subset of a data set that was used by Pretzsch et al. [10], where many urban tree species, including those dealt within the study at hand, are assigned to a small set of allometric types. This suggests that our findings can at least be roughly generalized for other species from the same allometric type and the same climate zone, and that they are representative for typical urban trees under the respective conditions.

In this context, the advantage of using allometric relations in contrast to other equation types is their strong foundation in biological theory. Thus, they are more than a mere description of a data set within the bounds of the sampled tree dimensions, as the parameter estimates transport direct biological information. An important consequence of this fact, allometric relationships can be extrapolated much more reliably than usual best-data-fit models. Species that show similar allometry can actually be considered to be comparable in terms of the variables involved. Furthermore, the allometry between tree size and size growth allows us to include temporal dynamics in our study, which are meaningful, albeit less precise, even when extrapolated due to their foundation in biological theory.

\subsection{Growth and Space Requirements of Urban Trees Based on Allometric Relationships}

Tree size and structure as described by tree allometry determine most functions and services of urban trees, such as shading, carbon fixation, or aesthetic embellishment. This underlines the relevance of a correct and species-specific quantification of tree allometry, which is in the focus of the study. Our continent-overarching study revealed the considerable extent to which allometry, and thus functions and services, can vary between species and change with proceeding tree ontogenesis. The study arrives at quantifying the allometry of six tree species common in urban environments. The quantification is relevant for practical planting guidelines for urban trees, for improving urban tree growth models, and parameterizing integrated tools for urban landscape planning.

The fundamental relationship of our analysis between basal area and basal area increment, which gives us the possibility of tracing back stem diameter growth and delivering us a sound scaling relationship, is based on increment cores. The results of our projected allometric relationships show that there are interspecific differences in urban tree allometry. The relationship of stem diameter to tree height shows the highest scaling parameter for K. senegalensis $\left(\beta_{1}=0.76\right)$ in Hanoi and lowest for Q. nigra $\left(\beta_{1}=0.23\right)$ in Houston. For $\beta_{0}$ only K. senegalensis $\left(\beta_{0}=-0.13\right)$ shows an unexpected negative value, all other species have positive values with the highest for $Q$. nigra $\left(\beta_{0}=1.81\right)$. In comparison to this, allometric exponents for the relationship of stem diameter to crown radius are in a smaller range. The scaling factors are positive for all species and in a very narrow range ( $\beta_{1}=0.43$ for $T$. cordata in Berlin, $\beta_{0}=0.71$ for $A$. cunninghamii in Brisbane). The lowest allometric exponent is $\beta_{0}=-1.39$ for A. cunninghamii and is the highest for T. cordata with $\beta_{0}=-0.03$. The results indicate that the growth of each species is individually based. Height growth, for example, increases from A. hippocastanum over P. $x$ hispanica and A. cunninghamii to K. senegalensis, while crown radius expands from A.cunninghamii over A. hippocastanum and P. $x$ hispanica to $Q$. nigra. These differences in growth dynamics for the specific species are highly relevant for urban forestry managers and planers. They need to know the space requirements of different species and how they will expand in the future in order to avoid potential conflicts with urban infrastructure. 
Pretzsch et al. [22] state that interspecies differences in tree allometry exist in forest stands. They applied a similar method as in the present study and highlighted that competition can change plant morphology, and that allometric relationships represent structural configurations of forest stands on a species-specific or a general scaling level. Their analysis was based on stem slices of different tree species from forest stands in southern Germany.

The results of the present study show that differences in tree allometry are not only present in forest stands due to competition, but are similarly found in urban areas. Pretzsch et al. [10] also investigated crown allometry of different urban tree species, but without taking the temporal dynamic of the species into account. Their findings resulted in five allometric crown extension types, which also covered a distinct range of expansion and showed species-specific differences. These allometry types can also serve as a means of generalizing the results shown in this study.

\subsection{Impact of Paved Surface Area on Urban Tree Growth}

Our results show evidence that the restricted non-paved area limits tree growth in urban areas. Thereby, we could demonstrate that the level of growth limitation due to spatial confinement by sealed surfaces is species-specific.

This finding might be explained by water supply and the tree species' water storage capacity. Quigley [18] assumes that urban tree growth is slower than in forest stands due to the fact that a distinct proportion of the roots is below the pavement, and in this way is cut off from precipitation water. The reduction of water supply might be the main disadvantage of the restricted non-paved area affecting tree growth. The water storage capacity, which is very limited in the case of paved surfaces, is investigated for different tree species by Xiao and McPherson [13]. They state that this capacity is very species-specific and age-dependent.

Another study showed that the pavement type and profile design have an influence on tree growth, as well as the compaction, but that the pavements themselves do not cause a reduced growth rate [23]. We used the area of non-paved surface as a parameter for the influence of restricted area and found a trend for species-specific growth reduction with increasing restricted area.

The conflicts of roots with urban infrastructure are reviewed by Randrup et al. [35] in the way of analyzing the most relevant factors causing problems with tree roots in urban areas. As main factors they list among other things: species with a large maturity size, fast growing species, trees planted in restricted soil volumes, shallow irrigation, restricted distance between tree and sidewalk, and, in general, trees older than 15 to 20 years. Of these factors the restricted soil volume and shallow irrigation are likely to be given if the non-paved surface area is limited. Due to this limitation in non-paved area our analysis showed a significantly reduced growth, especially for K. senegalensis.

\subsection{Comparison of Biomass and Carbon Storage Capacities of Different Urban Tree Species}

McPherson et al. [7] investigated the differences in biomass between forest and urban trees and concluded that forest trees on average contain $20 \%$ more biomass than urban trees at a given height and stem diameter. Following their suggestion, we multiplied the outcomes obtained with the traditional biomass equations with a factor of 0.8 in order to achieve more realistic estimates for our urban trees. This factor is also considered in the i-Tree Eco/Urban Forest Effects (UFORE) model developed in the USA [36]. In contrast, Russo et al. [37] did not use such a factor for their study in Bolzano, Italy, due to their assumption that not all urban trees are open-grown. McHale $e t$ al. [6] also compared forest and urban biomass values and equations and stated that the value of $20 \%$ difference in biomass should be re-evaluated.

In Table 7 the results of two other urban tree studies on $C$ storage $[8,9]$ are compared with the values of the present study. For $T$. cordata the $C$ storage values found by Moser $e t$ al. [8] are in a similar range to our findings. Both studies investigated T. cordata trees in German cities, which means that both studies took place within the same climate region. The minimum and mean $C$ storage values of the present study are higher, due to the fact that less small trees were sampled and the mean diameter 
is higher. Again, Moser et al. [8] did not apply the correction factor of 0.8 and Yoon et al. [9] used it for avoiding an overestimation of the urban tree biomass for their estimations. Despite the fact that the two studies were done in different climate regions, and assuming that the two studied Platanus species (P. $x$ hispanica and P. orientalis) show the same growth patterns, the $C$ storage of the tree individuals fit together when based on their diameter.

Table 7. Comparison of carbon storage capacity based on the estimation of above ground woody biomass for trees in the present study with other studies in urban areas and the related diameter range.

\begin{tabular}{ccccc}
\hline \multirow{2}{*}{ Species } & \multicolumn{3}{c}{ C Storage (kg/tree) } & $\mathbf{d}(\mathbf{c m})$ \\
\cline { 2 - 5 } & Min & Mean & Max & Min-Max \\
\hline Platanus $x$ hispanica & 259 & 702 & 2956 & $40-144$ \\
Platanus orientalis ${ }^{1}$ & 83 & - & 406 & $23-48$ \\
Tilia cordata & 71 & 303 & 1087 & $25-81$ \\
Tilia cordata ${ }^{2}$ & 8 & 196 & 1341 & $6-107$ \\
\hline \multicolumn{4}{c}{${ }^{1}$ Data from Yoon et al. $\left[\right.$ [9]; ${ }^{2}$ Data from Moser et al. [8]. }
\end{tabular}

These results show that although a comparison of different studies is difficult due to different diameter ranges and different equations that might be used for the estimation, still the findings indicate that a tree species performs in a similar range on different sampling locations.

\subsection{Carbon Storage Capacity of T. Cordata on City Scale}

The present study estimates the temporal dynamic of urban tree growth and expansion. On this basis an estimation of the annual net carbon fixation of urban trees' woody biomass for a whole city is possible. Different studies [37-39], which quantified above-ground carbon storage on a city-wide scale, show that more research in this field is needed. For deriving a plausible estimation on the city scale the diameter distribution of the tree collective has to be known. For T. cordata a sample of 61,000 trees in Berlin [40] delivered us this distribution. In total, T. cordata trees amounted to 155,000 in 2014, by having a share of $35 \%$ of all street trees in Berlin [40]. By using the above mentioned biomass equation for T. cordata [33], which takes the diameter and the tree height into account, the carbon storage of this species sums up to 31.17 million tons $C$. On the base of the mean tree age of the respective diameter class the annual net average C-fixation of one single lime tree was calculated with $2.8 \mathrm{~kg} \mathrm{C}$ year $^{-1}$, which results in an annual C-fixation for all lime trees in Berlin of $430 \mathrm{t} C$ year $^{-1}$. Assuming a per capita $C$ consumption of $1.5 \mathrm{t} C$ year $^{-1}$ for the year 2012 for Berlin [41], the annual carbon-fixation of lime trees corresponds to a carbon consumption of 284 inhabitants of Berlin.

Comparing the average value of $2.8 \cdot \mathrm{kg} \mathrm{C} \mathrm{year}^{-1}$ of the present study to a similar study from Italy by Russo et al. [37] shows that with $2.8 \mathrm{~kg} \mathrm{C}$ year $^{-1}$ our estimation is out of his range, which lies between 9.79 to $43.06 \mathrm{~kg} \mathrm{C}$ year $^{-1}$. It has to be mentioned though that $T$. cordata represents the lowest level of biomass production and carbon sequestration from our investigated species. This means that the other investigated species are within the range of Russo's values, which represent diverse tree species. Further, the differences between the studies might be due to the fact that the study by Russo et al. [37] included trees from urban areas as well as forest stands.

Schreyer et al. [42] derived the carbon storage per tree of different structure types in the City of Berlin. They list a value of $1,028,427 \mathrm{t}$ carbon for the entire city of Berlin. In comparison, we quantified the value of $31,170 \mathrm{tC}$ for 155,000 Tilia trees. If we take into account that $T$. cordata has a low $\mathrm{C}$ fixation rate compared to other species, and that just one third of Berlin's vegetation is represented with our selection, the total values of the two studies might fit together. 


\section{Conclusions}

In summary, the results show the species-specific allometries of a set of typical urban trees worldwide, under the conditions they are typically found and best adapted to, by taking the temporal dynamic into account. The enlargement of diameter, tree height, and crown radius size are very species-specific and vary between the six investigated urban tree species. It can also be shown that the impact of paved surface inhibits tree growth. A significant impact of the non-paved area was found for the species A. hippocastanum in Munich and K. senegalensis in Hanoi. The estimations for above ground biomass are also species-specific and show the highest values for the deciduous species $Q$. nigra in Houston and the lowest for T. cordata in Berlin.

Our study gives statistically solid quantitative information about how typical urban tree species develop worldwide with specific regard given towards space requirements, which we deem useful for urban managers. Linking this information with the allometric species types as identified in Pretzsch et al. [10], the applicability of our study is beyond the species investigated here. With this knowledge better adaption of treatments for urban trees, which are in potential conflict with urban infrastructure, is possible; this information might be useful in supporting the benefits of urban trees. As a result, the additional costs for tree maintenance and care, which are well reported [2], can be reduced and a more effective way of managing might be possible.

Future research in this field is needed for an extended understanding of the growth behavior of urban trees and its temporal dynamic, specifically in relation to anthropogenic decisions, like paving surfaces. Last but not least, further investigations on urban tree biomass and carbon storage worldwide are important against the background of rising interest in urban air quality.

We based our study on both countries with long experience in urban tree research and countries that presently have begun caring for and investigating urban trees. As such, we tried to contribute to a continuous improvement of the appreciation, research, and knowledge base of urban trees worldwide.

Acknowledgments: Thanks to the AUDI Environmental Foundation for funding the project "Response of urban trees on climate change" and the several city ministries and forest services for the allowance of coring and measuring trees and for supporting the search for the trees. This work was supported by the German Research Foundation (DFG) and the Technical University of Munich (TUM) in the framework of the Open Access Publishing Program. The authors also want to thank two anonymous reviewers for their constructive and helpful comments on previous versions of the manuscript.

Author Contributions: Hans Pretzsch, Thomas Rötzer, and Enno Uhl conceived and designed the experiment; Jens Dahlhausen performed the experiments and analyzed the data; Peter Biber contributed statistical analysis tools; Jens Dahlhausen and Peter Biber wrote the paper. Thomas Rötzer and Enno Uhl revised the manuscript.

Conflicts of Interest: The authors declare no conflict of interest. The founding sponsors had no role in the design of the study; in the collection, analyses, or interpretation of data; in the writing of the manuscript, and in the decision to publish the results.

\section{Abbreviations}

The following abbreviations are used in this manuscript:

$\begin{array}{ll}\text { awb } & \text { aboveground woody biomass } \\ \text { ba } & \text { basal area } \\ \text { cb } & \text { crown base } \\ \text { cr } & \text { mean crown radius } \\ \text { cpa } & \text { crown projection area } \\ \text { hcb } & \text { height to crown base } \\ \text { iba } & \text { basal area increment } \\ \text { npa } & \text { non-paved area } \\ \text { OLS } & \text { Ordinary least squares } \\ \text { SCON } & \text { Spatial confinement of a tree }\end{array}$




\section{Appendix A}

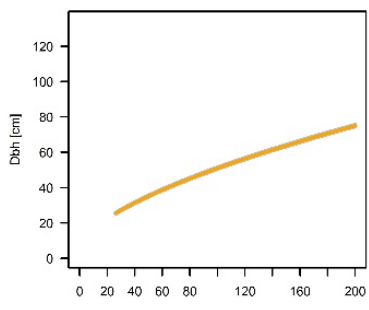

Age lyear

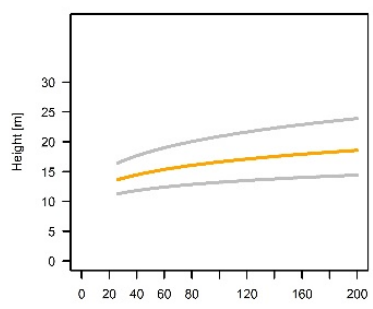

Age lyear

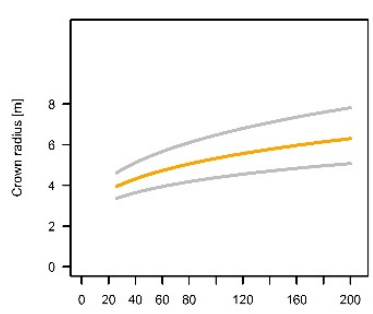

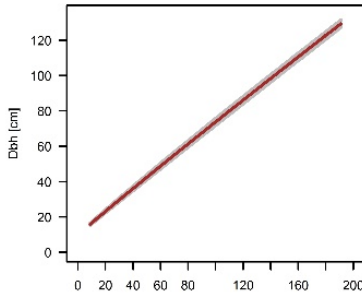

Age lyearl

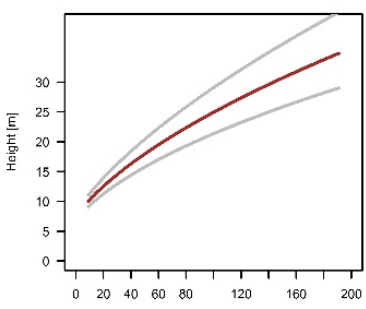

Age yyearl

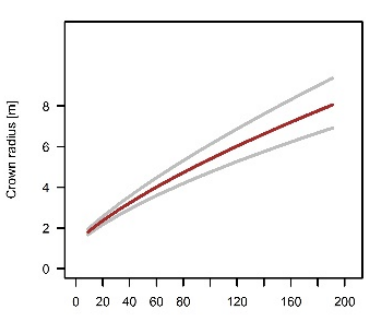

Age vyeal
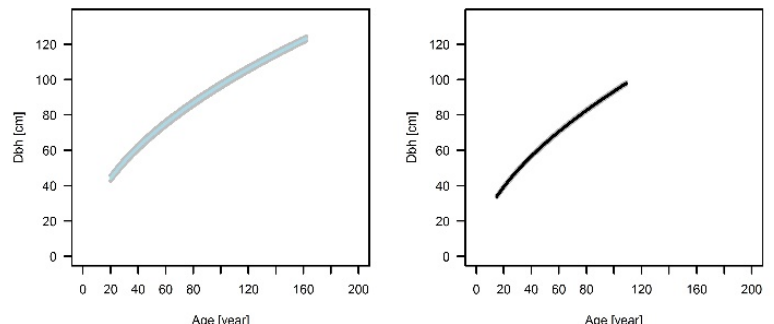

Age Evear
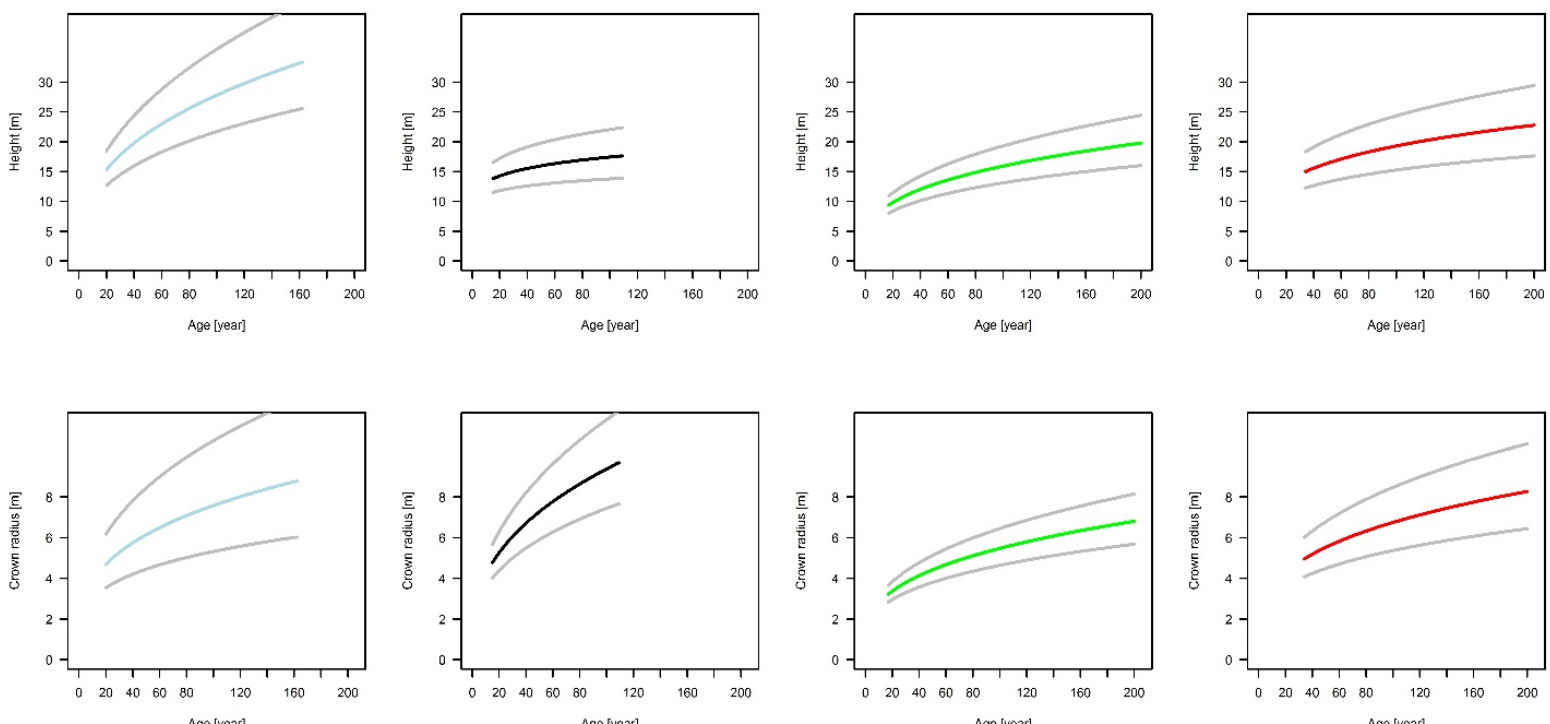

Figure A1. Allometric relationships for diameter at breast breast height (upper line), tree height (middle line) and crown radius (lower line) based on allometric model parametrizations for all six tree species (based on values of Tables 3-5). The coloured lines show the best-fit lines, and the grey lines indicate the visualized standard error of $\beta_{1}$. 


\section{References}

1. Escobedo, F.J.; Kroeger, T.; Wagner, J.E. Uban forests and pollution mitigation: Analyzing ecosystem services and disservices. Environ. Pollut. 2011, 159, 2078-2087. [CrossRef] [PubMed]

2. Mullaney, J.; Lucke, T.; Trueman, S.J. A review of benefits and challenges in growing street trees in paved urban environments. Landsc. Urban Plan. 2015, 134, 157-166. [CrossRef]

3. McPherson, E.G.; Muchnick, J. Effect of street tree shade on asphalt concrete pavement performance. J. Arboric. 2005, 31, 303.

4. Livesley, S.J.; McPherson, G.M.; Calfapietra, C. The Urban Forest and Ecosystem Services: Impacts on Urban Water, Heat, and Pollution Cycles at the Tree, Street, and City Scale. J. Environ. Qual. 2016, 45, 119-124. [CrossRef] [PubMed]

5. Quigley, M.F. Fanklin Park: 150 years of changing design, disturbance, and impact on tree growth. Urban Ecosyst. 2002, 6, 223-235. [CrossRef]

6. McHale, M.R.; Burke, I.C.; Lefsky, M.A.; Peper, P.J.; McPherson, E.G. Uban forest biomass estimates: Is it important to use allometric relationships developed specifically for urban trees? Urban Ecosyst. 2009, 12, 95-113. [CrossRef]

7. McPherson, G.E.; Nowak, D.J.; Rowntree, R.A. Cicago's Urban Forest Ecosystem: Results of the Chicago Urban Forest Climate Project; United States Department of Agriculture: Radnor, PA, USA, 1994.

8. Moser, A.; Rötzer, T.; Pauleit, S.; Pretzsch, H. Structure and ecosystem services of small-leaved lime (Tilia cordata Mill.) and black locust (Robinia pseudoacacia L.) in urban environments. Urban For. Urban Green. 2015, 14, 1110-1121. [CrossRef]

9. Yoon, T.K.; Park, C.-W.; Lee, S.J.; Ko, S.; Kim, K.N.; Son, Y.; Lee, K.H.; Oh, S.; Lee, W.-K.; Son, Y. Allometric equations for estimating the aboveground volume of five common urban street tree species in Daegu, Korea. Urban For. Urban Green. 2013, 12, 344-349. [CrossRef]

10. Pretzsch, H.; Biber, P.; Uhl, E.; Dahlhausen, J.; Rötzer, T.; Caldentey, J.; Koike, T.; van Con, T.; Chavanne, A.; Seifert, T.; et al. Crown size and growing space requirement of common tree species in urban centres, parks, and forests. Urban For. Urban Green. 2015, 14, 466-479. [CrossRef]

11. Gill, S.E.; Handley, J.F.; Ennos, A.R.; Pauleit, S. Adapting cities for climate change: The role of the green infrastructure. Built Environ. 2007, 3, 115-133. [CrossRef]

12. McPherson, E.G.; Nowak, D.; Heisler, G.; Grimmond, S.; Souch, C.; Grant, R.; Rowntree, R. Quantifying urban forest structure, function, and value: The Chicago Urban Forest Climate Project. Urban Ecosyst. 1997, 1, 49-61. [CrossRef]

13. Xiao, Q.; McPherson, E.G. Srface water storage capacity of twenty tree species in Davis, California. J. Environ. Qual. 2016, 45, 188-198. [CrossRef] [PubMed]

14. Scharenbroch, B.C.; Morgenroth, J.; Maule, B. Tree species suitability to bioswales and impact on the urban water budget. J. Environ. Qual. 2016, 45, 199-206. [CrossRef] [PubMed]

15. Escobedo, F.J.; Clerici, N.; Staudhammer, C.L.; Corzo, G.T. Scio-ecological dynamics and inequality in Bogotá, Colombia's public urban forests and their ecosystem services. Urban For. Urban Green. 2015, 14, 1040-1053. [CrossRef]

16. Anderson, S.T.; West, S.E. Oen space, residential property values, and spatial context. Reg. Sci. Urban Econ. 2006, 36, 773-789. [CrossRef]

17. Peper, P.J.; Alzate, C.P.; McNeil, J.W.; Hashemi, J. Allometric equations for urban ash trees (Fraxinus spp.) in Oakville, Southern Ontario, Canada. Urban For. Urban Green. 2014, 13, 175-183. [CrossRef]

18. Quigley, M.F. Sreet trees and rural conspecifics: Will long-lived trees reach full size in urban conditions? Urban Ecosyst. 2004, 7, 29-39. [CrossRef]

19. Sanders, J.R.; Grabosky, J.C. 20 years later: Does reduced soil area change overall tree growth? Urban For. Urban Green. 2014, 13, 295-303. [CrossRef]

20. Blunt, S.M. Trees and pavements-Are they compatible? Arboric. J. 2008, 31, 73-80. [CrossRef]

21. Kirkpatrick, J.B.; Davison, A.; Daniels, G.D. Rsident attitudes towards trees influence the planting and removal of different types of trees in eastern Australian cities. Landsc. Urban Plan. 2012, 107, 147-158. [CrossRef]

22. Pretzsch, H.; Dauber, E.; Biber, P. Species-Specific and Ontogeny-Related Stem Allometry of European Forest Trees: Evidence from Extensive Stem Analyses. For. Sci. 2013, 59, 290-302. [CrossRef] 
23. Morgenroth, J. Root growth response of Platanus orientalis to porous pavements. Arboric. Urban For. 2011, 37, 45 .

24. Assmann, E. Waldertragskunde: Organische Produktion, Struktur, Zuwachs und Ertrag von Waldbeständen; BLV Verlagsgesellschaft: München, Germany, 1961.

25. Preuhsler, T. Ertragskundliche Merkmale oberbayerischer Bergmischwald-Verjüngungsbestände auf kalkalpinen Standorten im Forstamt Kreuth. Forstwiss. Cent. 1981, 100, 313-345. [CrossRef]

26. Niklas, K.J. Pant allometry: Is there a grand unifying theory? Biol. Rev. 2004, 79, 871-889. [CrossRef] [PubMed]

27. Enquist, B.J.; Niklas, K.J. Ivariant scaling relations across tree-dominated communities. Nature 2001, 410, 655-660. [CrossRef] [PubMed]

28. West, G.B.; Enquist, B.J.; Brown, J.H. A general quantitative theory of forest structure and dynamics. Proc. Natl. Acad. Sci. USA 2009, 106, 7040-7045. [CrossRef] [PubMed]

29. Jenkins, J.C.; Chojnacky, D.C.; Heath, L.S.; Birdsey, R.A. Ntional-scale biomass estimators for United States tree species. For. Sci. 2003, 49, 12-35.

30. Eamus, D.; McGuinness, K.; Burrows, W.W. Review of Allometric Relationships for Estimating Woody Biomass for Queensland, the Northern Territory and Western Australia; Technical Report No. 5a; Australian Greenhouse Office: Canberra, Australia, 2000.

31. Clément, J. Estimation des volumes et de la productivité des formations mixtes foresiéres et graminées tropicales. Bois For. Trop. 1982, 198, 35-58.

32. Clark, A.I.; Phillips, D.R.; Frederick, D.J. Wight, Volume, and Physical Properties of Major Hardwood Species in the Gulf and Atlantic Coastal Plains; United States Department of Agriculture: Radnor, PA, USA, 1985.

33. Čihák, T.; Hlásny, T.; Stolariková, R.; Vejpustková, M.; Marušák, R. Functions for the aboveground woody biomass in Small-leaved lime (Tilia cordata Mill.)/Funkce pro hodnocení biomasy nadzemních částí lípy malolisté (Tilia cordata Mill.). For. J. 2014, 60, 150-158. [CrossRef]

34. Penman, J.; Gytarsky, M.; Hiraishi, T.; Krug, T.; Kruger, D.; Pipatti, R.; Buendia, L.; Miwa, K.; Ngara, T.; Tanabe, K.; et al. Good Practice Guidance for Land Use, Land-Use Change and Forestry; Penman, J., Gytarsky, M., Hiraishi, T., et al., Eds.; IPCC National Greenhouse Gas Inventories Programme: Kanagawa, Japan, 2003.

35. Randrup, T.B.; McPherson, E.G.; Costello, L.R. A review of tree root conflicts with sidewalks, curbs, and roads. Urban Ecosyst. 2001, 5, 209-225. [CrossRef]

36. Nowak, D.J.; Crane, D.E. The Urban Forest Effects (UFORE) Model: Quantifying Urban Forest Structure and Functions. Available online: http://www.nrs.fs.fed.us/pubs/gtr/gtr_nc212/gtr_nc212_714.pdf (accessed on 22 March 2016).

37. Russo, A.; Escobedo, F.J.; Timilsina, N.; Schmitt, A.O.; Varela, S.; Zerbe, S. Assessing urban tree carbon storage and sequestration in Bolzano, Italy. Int. J. Biodivers. Sci. Ecosyst. Serv. Manag. 2014, 10, 54-70. [CrossRef]

38. Davies, Z.G.; Edmondson, J.L.; Heinemeyer, A.; Leake, J.R.; Gaston, K.J. Mpping an urban ecosystem service: Quantifying above-ground carbon storage at a city-wide scale: Urban above-ground carbon storage. J. Appl. Ecol. 2011, 48, 1125-1134. [CrossRef]

39. Lee, J.-H.; Ko, Y.; McPherson, E.G. Te feasibility of remotely sensed data to estimate urban tree dimensions and biomass. Urban For. Urban Green. 2016, 16, 208-220. [CrossRef]

40. GRIS. Straßenbäume in Berlin-Bestand nach Hauptgattungen in den Berliner Bezirken. Available online: http://www.stadtentwicklung.berlin.de/umwelt/stadtgruen/stadtbaeume/de/daten_fakten/ downloads/ausw_139.pdf (accessed on 31 December 2014).

41. Dank, H. Statistischer Bericht E IV 4-j/07 Energie-und $\mathrm{CO}_{2}$-Bilanz im Land Brandenburg 2007. Available online: https://opus4.kobv.de/opus4-slbp/frontdoor/index/index/year/2010/docId/2218 (accessed on 16 March 2016).

42. Schreyer, J.; Tigges, J.; Lakes, T.; Churkina, G. Using Airborne LiDAR and QuickBird Data for Modelling Urban Tree Carbon Storage and Its Distribution-A Case Study of Berlin. Remote Sens. 2014, 6, 10636-10655. [CrossRef]

(C) 2016 by the authors; licensee MDPI, Basel, Switzerland. This article is an open access article distributed under the terms and conditions of the Creative Commons Attribution (CC-BY) license (http://creativecommons.org/licenses/by/4.0/). 